Supporting Information

\title{
The First Full Spectrum Visible LED Light Activated Antibacterial System Realized by Optimized $\mathrm{Cu}_{2} \mathrm{O}$ Crystals
}

Xiaotong Shi ${ }^{\dagger}$, Chaowen Xue ${ }^{\dagger}$, Fang Fang ${ }^{\ddagger}$, Xiangwei Song ${ }^{\dagger}$, Fen Yu ${ }^{\S}$, Miaoxing Liu ${ }^{\S}$, Zhipeng $\mathrm{Wei}^{\dagger}$, Xuan Fang ${ }^{\dagger}$, Dongxu Zhao ${ }^{\dagger}$, Hongbo Xin ${ }^{\dagger}$, Xiaolei Wang ${ }^{\dagger, \S} *$

${ }^{\dagger}$ Institute of Translational Medicine, NanChang University, NanChang, Jiangxi, 330031, China

${ }^{\S}$ College of Chemistry, NanChang University, NanChang, Jiangxi, 330031, China

${ }^{\ddagger}$ National Engineering Technology Research Center for LED on Si Substrate, NanChang University, NanChang, Jiangxi, 330047, China

${ }^{\ddagger}$. State Key Laboratory of High Power Semiconductor Laser of ChangChun University of Science and Technology, ChangChun, Jinlin, 130022, China

${ }^{f}$ Changchun Institute of Optics, Fine Mechanics and Physics, Chinese Academy of Sciences, ChangChun, Jilin, 130033, China

*E-mail: wangxiaolei@ncu.edu.cn 


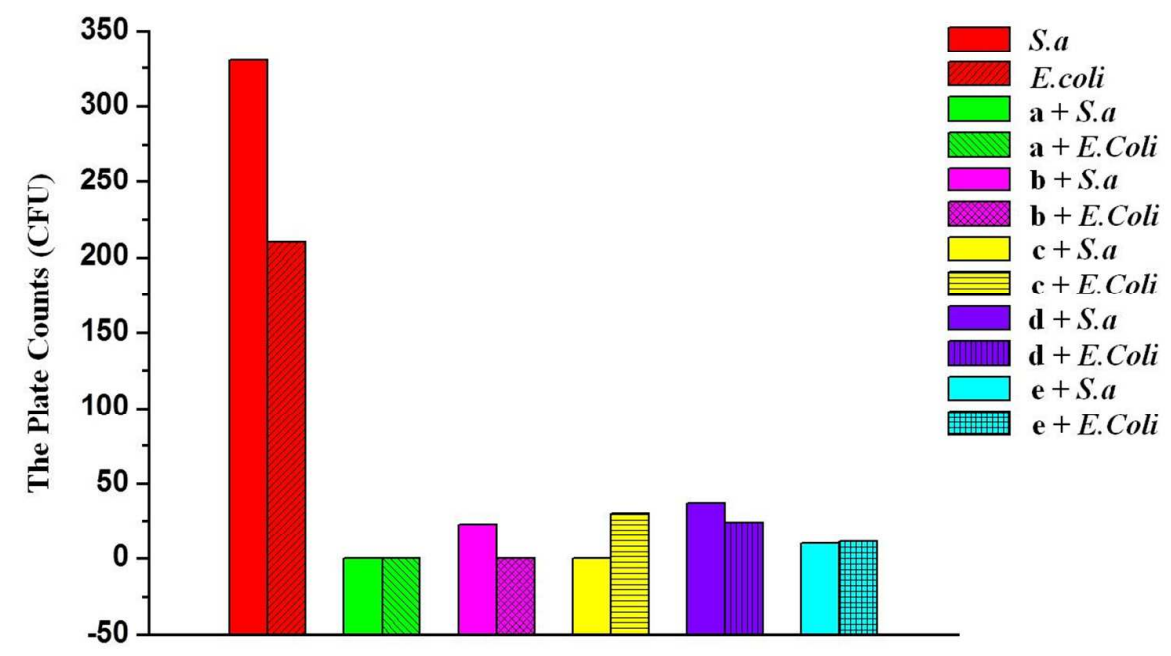

Figure S1. The antibacterial results of five different morphological $\mathrm{Cu}_{2} \mathrm{O}$ crystals against S.a and E.coli. (a: cube; b: edge-truncated octahedra; c: edge- and corner-truncated octahedra; d: truncated octahedra; e: octahedra.) 


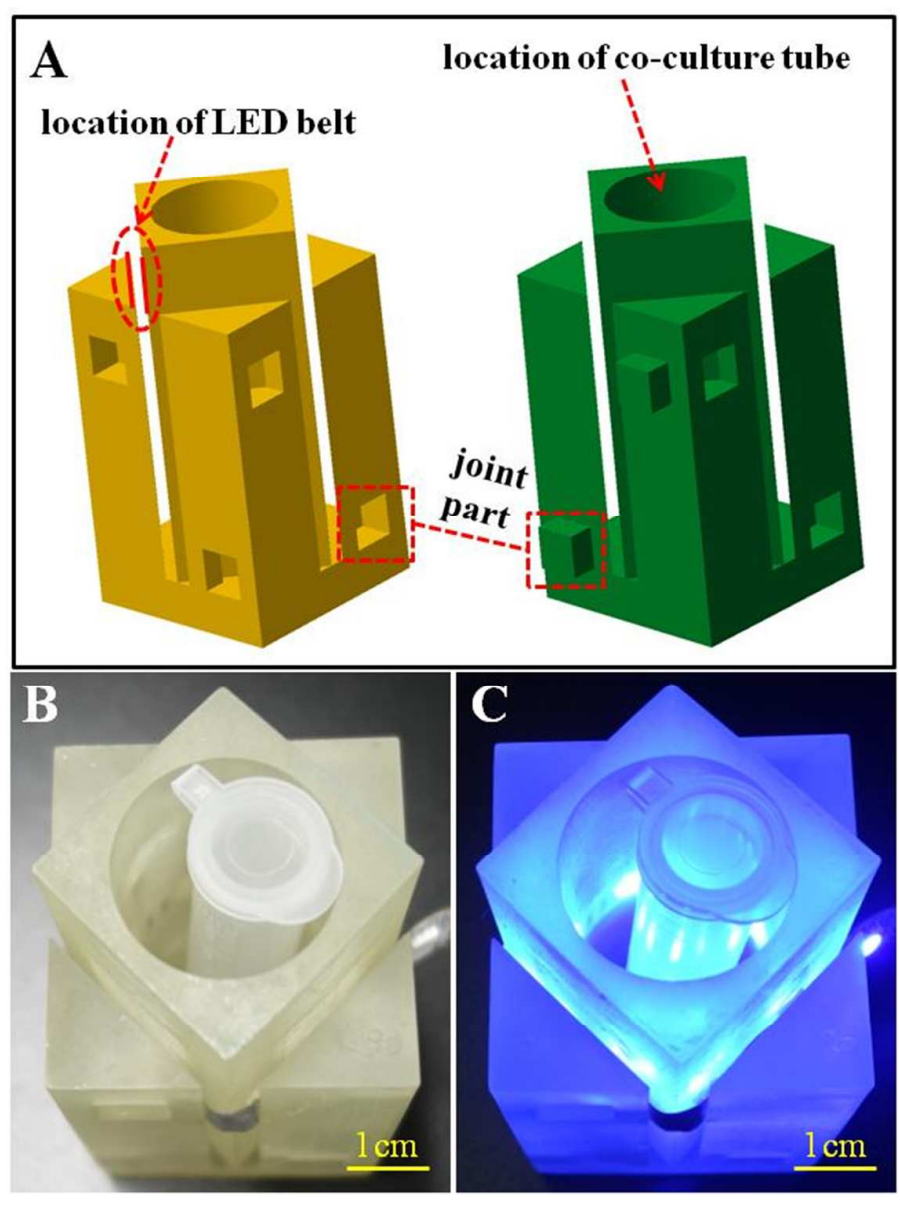

Figure S2. The 3D model (A) of modular experimental apparatus and corresponding optical images before (B) and after (C) the LED belts being switched on. The LED belts could be accurately placed in the apparatus without external auxiliary. Furthermore, different illumination intensity could be achieved by changing the diameter of the round hole in the middle. 


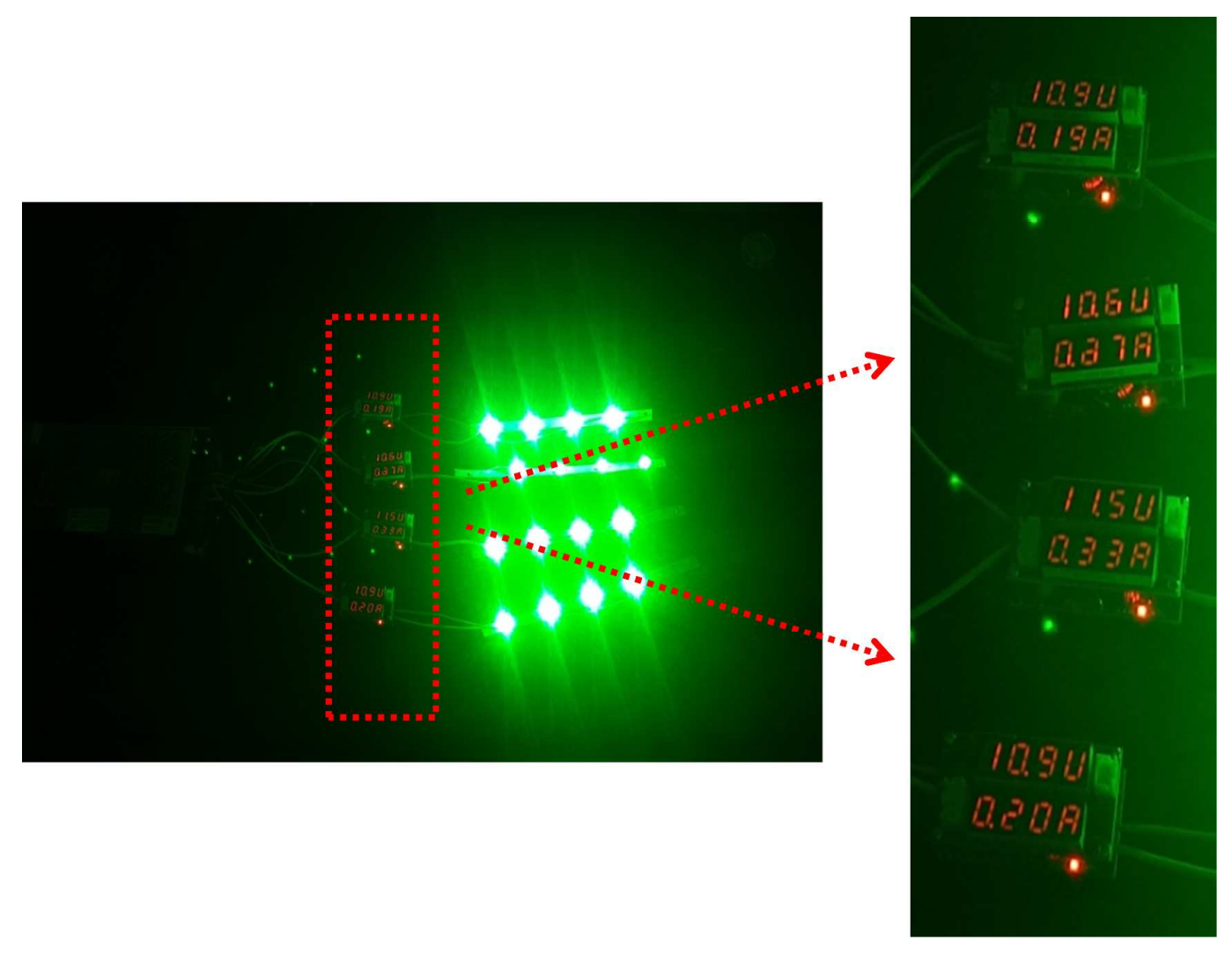

Figure S3. The device that be employed to accurately control the power of LED belts.

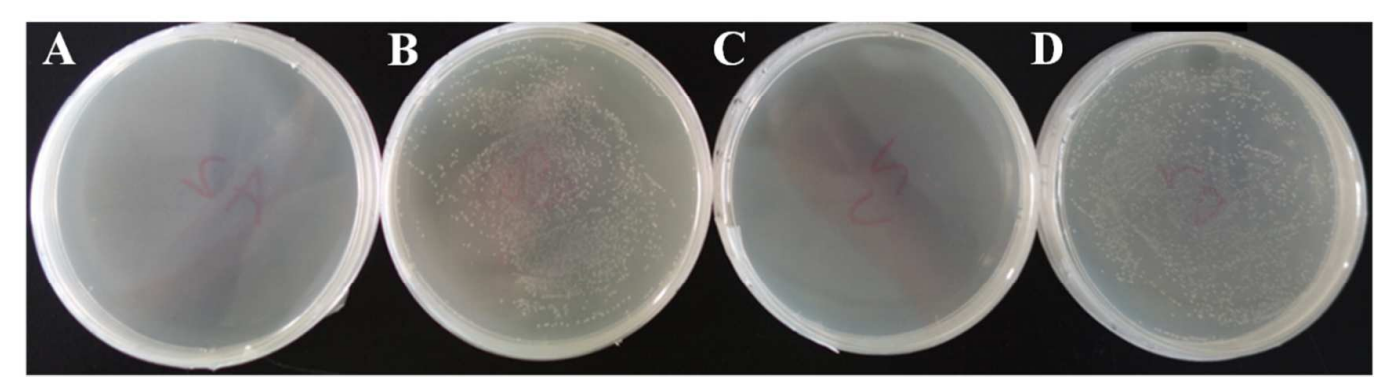

Figure S4. The antibacterial results of non-woven fabrics loaded with cubic $\mathrm{Cu}_{2} \mathrm{O}$ crystals against E.coli. (A: non-woven fabric loaded with $\mathrm{Cu}_{2} \mathrm{O}$ under the irradiation of blue LED; B: the irradiation of blue LED only; C: non-woven fabric loaded with $\mathrm{Cu}_{2} \mathrm{O}$ without the irradiation of blue LED; D: control). 